\title{
BLOGS DE CIÊNCIA: PRÁTICAS DE CUIDADO DE SI DO CIENTISTA CONTEMPORÂNEO
}

\author{
SCIENCE BLOGS: CARE OF THE SELF PRACTICES OF CONTEMPORARY \\ SCIENTIST \\ BLOGS DE CIENCIA: PRÁCTICAS DE CUIDADO DE SÍ DEL \\ INVESTIGADOR CONTEMPORANEO
}

\author{
Natália Martins Flores \\ Doutoranda em Comunicação/PPGCOM UFPE \\ nataliflores@gmail.com
}

\section{Resumo}

Este trabalho trata do fenômeno de apropriação pela comunidade científica de ferramentas de autopublicação na internet - os blogs de ciência - relacionando-o com o conceito de cuidado de si de Michel Foucault e a construção do ethos do sujeito- pesquisador na contemporaneidade. Investigam-se 20 blogs de ciência escritos por pesquisadores da rede brasileira ScienceBlogs Brasil. Reflete-se sobre esses blogs como indícios de abertura da comunidade científica brasileira a não-cientistas.

Palavras-chave: Blog, Ethos. Comunicação.

\begin{abstract}
This paper explores the phenomenon of appropriation by the scientific community of selfpublishing tools on the Internet - science blogs - relating it with the concept of the Care of the Self of Michel Foucault and the construction of the ethos of the researcher in contemporary times. Twenty blogs written by researchers of the Brazilian network Science Blogs Brazil are investigated. We reflect about these blogs as evidence of an opening of the Brazilian scientific community to non-scientists.
\end{abstract}

Key-words: Blog. Ethos. Communication.

\section{Resumen}

La investigación explora el fenómeno de apropiación de parte de la comunidad científica de las herramientas de auto-publicación en Internet - los blogs de ciência - y lo relaciona al concepto de cuidado de sí de Michel Foucault y la construcción del ethos del sujetoinvestigador en tiempos contemporaneos. Se investigan 20 blogs de ciência escritos por investigadores de la red brasileña ScienceBlogs Brasil. Se refleja aun a cerca de los nuevos médios de comunicación en tanto que prueba de apertura de la comunidad científica hacia la comunidad no científica.

Palabras-clave: Blog. Ethos. Comunicación. 


\section{INTRODUÇÃO}

As atividades de divulgação científica são atualmente valorizadas como modo de melhorar a comunicação entre instituições de pesquisa e sociedade. No Brasil, observa-se um movimento de agências de fomento de pesquisa na promoção de práticas de educação e divulgação científica realizadas por pesquisadores, materializadas, por exemplo, na criação de uma seção na plataforma Lattes do Conselho Nacional de Desenvolvimento Científico e Tecnológico (CNPq) para registro de atividades desta ordem. Além da esfera institucional, aparecem também iniciativas individuais de comunicação de ciência para não-cientistas, expressas pelos blogs de ciência escritos por estudantes de pós-graduação e pesquisadores.

A emergência dos blogs de ciência de pesquisadores relaciona-se ao cenário de apropriação de novas tecnologias pela comunidade científica, reconstruindo práticas desta comunidade. Neste artigo, empreendemos um esforço inicial no sentido de refletir sobre o fenômeno de apropriação de espaços de autopublicação na internet pela comunidade científica, relacionando-o com o conceito de cuidado de si de Michel Foucault e a construção contemporânea do ethos do sujeito-pesquisador. Também tentamos compreender as motivações do cientista blogueiro para postar em blogs, utilizando como exemplo os blogs escritos por pesquisadores do condomínio brasileiro de blogs de ciência ScienceBlogs Brasil.

\subsection{A negação da espiritualidade}

Refletir sobre as relações que se estabelecem entre o fenômeno de emergência de blogs de ciência e a formação do ethos do pesquisador contemporâneo requer que discorramos sobre a construção do que é ser cientista e do que é fazer ciência ao longo da trajetória histórica das ciências e na constituição da matriz cientificista moderna ocidental ${ }^{1}$. Para realizar essa breve genealogia, tornam-se interessantes as problematizações de Michel Foucault sobre as estruturas de subjetivação, ou seja, os modos como o indivíduo liga-se a sistemas de verdade e produz-se como sujeito.

\footnotetext{
${ }^{1}$ Em trabalho anterior (FLORES, 2011), tratamos o cientificismo como uma matriz de pensamento Ocidental, um modelo surgido na formação ideológica da modernidade que configurou os sistemas institucionais, as atitudes e os pensamentos do homem moderno acerca da sua realidade e do seu mundo. Nesse contexto, a crença na ciência cientificista e tecnicista ocorre como dominante.
} 
É na última fase de seu pensamento que Foucault desenvolve as questões relativas à subjetividade, principalmente nos cursos do Collège de France intitulados Subjectivité et verité (1981) e L’herméneutique du sujet (1982). Ao pretender traçar uma genealogia da subjetividade ocidental, o teórico expõe uma crítica ao sujeito fundador através do desvendamento dos processos históricos que nos moldam como sujeitos. Foucault afasta-se da tradição filosófica ao construir uma história da subjetividade exterior ao próprio conhecimento, observando as técnicas de olhar sobre si constituídas no Ocidente.

As reflexões de Foucault relacionam a constituição das subjetividades ocidentais contemporâneas à objetivação e ao conhecimento de si por meio da ciência. Nesta perspectiva, as técnicas de objetivação não se ligam apenas à constituição do sujeitopesquisador - objeto de investigação deste trabalho - mas configuram-se num contexto mais amplo e podem ser observadas na própria construção biopolítica do corpo humano. Na atualidade, a concepção de si, do que somos e do que pretendemos ser é engendrada quase que exclusivamente pela aparência e pelas técnicas médicas e científicas de cuidado com o nosso corpo.

Para Foucault (2004), parece que a construção da matriz de objetivação do corpo presente no pensamento ocidental advém do momento cartesiano, quando se dá a desvinculação entre dois conceitos unidos na Antiguidade grega: o cuidado de si (epiméleia heautoû) e o conhece-te a ti mesmo (gnôthi seautón). Essa cisão requalifica o conhecimento (conhece-te a ti mesmo), separando-o da espiritualidade e assumindo-o como o único modo de acesso à verdade.

Antes do momento cartesiano, o conhece-te a ti mesmo aparecia subordinado ao cuidado de si, sendo o último conceito um fundamento para o primeiro. O cuidado de si, ou epiméleia heautoû, se referia a uma atitude geral de encarar as coisas, uma atenção e forma de olhar para si, de conhecer a si mesmo, que transformava o sujeito (FOUCAULT, 2004). O conhecer a si mesmo não se vincula à objetivação do ser operada mais tarde pela ciência, mas sim a uma prática de retorno a si, prática de existência que permitiria ao sujeito acessar a verdade.

O conceito de verdade deste período é anterior ao momento cartesiano e, portanto, não se refere ao modo cientificista como empregamos o termo. Diferentemente da verdade racional da ciência, a qual é dada ao sujeito como simples ato do conhecimento, a verdade aqui referida pertence a uma matriz de espiritualidade e relaciona-se a um processo de transformação do sujeito, uma forma de vida do indivíduo ligada à iluminação deste na sua busca por um sentido à vida. 
A distinção entre a verdade espiritual, imbricada nos conceitos de conhece-te a ti mesmo e cuidado de si, e a verdade relacionada à matriz científica provoca questionamentos pertinentes. A preocupação de Foucault (2004) é justamente tentar compreender a razão de um conceito tão central na Antiguidade - o cuidado de si - ter perdido espaço no ocidente, a ponto de haver poucos teóricos que abordem a questão. Para isso, o teórico busca nos textos gregos os elementos iniciais da epiméleia heautoû, empreendendo a reconstituição de uma matriz espiritual que nos foi negada na construção do sujeito.

É interessante observar como o processo de legitimação do paradigma dominante de ciência integra-se à visão de mundo ocidental. A cisão entre espiritualidade e racionalidade ocorrida no momento cartesiano fez com que atribuíssemos valorações positivas à razão e negativas à espiritualidade. Neste sentido é que operam a exaltação da ciência como saber autorizado e a desvalorização da subjetividade e do lado espiritual, tidas como incapazes de trazer respostas ao homem. Tende-se a preocupar-se mais com o lado racional do ser humano - objetivado através dos métodos científicos - em detrimento do seu lado espiritual, sua necessidade de se transformar como sujeito.

A negação da espiritualidade relaciona-se ao processo de constituição da ciência moderna que, segundo comenta Boaventura Sousa Santos (2006), demarca fronteiras rígidas entre o saber científico e o não-científico. Mais do que criar fronteiras entre espiritualidade e ciência, a constituição do paradigma dominante de ciência qualifica o saber científico como único acesso à verdade, enquanto desqualifica saberes anteriores que não seguem métodos científicos.

A valorização do conhecimento marcou a própria construção cultural da divulgação científica e da relação cientista-leigo. No modelo do déficit, por exemplo, os valores atribuídos aos indivíduos na troca comunicativa são configurados de acordo com seu acesso ou não ao conhecimento científico. Assim, atribuem-se valorações positivas ao cientista como detentor do saber científico, responsável por iluminar o leigo, e negativas ao leigo, o qual não tem acesso a esse saber. A ciência ocorre como conhecimento necessário ao indivíduo, mas dificilmente questiona-se como ela poderia transformá-lo enquanto sujeito.

É por meio da matriz de pensamento da modernidade que se constrói socialmente o que é ser cientista e o que representa seguir uma carreira de pesquisa. Segundo discorre Hilton Japiassú (1982), a filiação à razão e aos ideais de neutralidade e precisão excluíram do campo epistemológico da ciência as valorações e interpretações do pesquisador, o qual é colocado em posição de imparcialidade. Os métodos racionais ajudam, então, a desumanizar o 
cientista ao restringir o máximo possível o fator de natureza humana e de espiritualidade que lhe são próprias.

Passa-se por um processo de negação da subjetividade que constrói a imagem do cientista como "um indivíduo ao abrigo das ideologias, dos desvios passionais e das tomadas de posição subjetivas ou valorativas” (JAPIASSÚ, 1975, p.11). Em muitos casos, a exclusão de motivações que levaram o pesquisador a realizar determinada pesquisa acaba por desvincular a ciência de um propósito exterior ao conhecimento pelo conhecimento. Assim, fazer ciência ${ }^{2}$ ocorre como uma prática apartada de suas motivações iniciais e atrelada puramente à objetividade.

De fato, é aí que reside a grande crítica de Foucault à modernidade e ao modo como se operou a cisão entre cuidado de si e conhece-te a ti mesmo, ou se preferirmos, entre a espiritualidade e a ciência. Essa separação fez com que concebêssemos como impossível uma ciência relacionada ao plano espiritual, às subjetividades. Assim se produziram as dicotomias entre objeto/sujeito que perduram até hoje em algumas áreas do conhecimento. Mais uma vez, a dicotomia produz irregularidades e tende a valorizar o conhecimento em detrimento da espiritualidade. Isso pode ser observado, por exemplo, no modo como hoje conhecemos muito mais dos objetos e da natureza das coisas que nos cercam do que da própria subjetividade humana, das nossas motivações e paixões.

A construção da ciência objetivada produz uma ambigüidade entre os membros da comunidade científica: ao mesmo tempo em que o cientista deve regularizar seu discurso conforme as regras de expressão oficial da ciência - reduzindo ao máximo a intervenção humana ao redigir relatórios e artigos científicos com linguagem impessoal - esse indivíduo conhece o relato verdadeiro da pesquisa, o qual inclui falhas e procedimentos por vezes não descritos no relatório final (BOURDIEU, 2008). Como não pode escrever de maneira subjetiva nos relatórios científicos, deixando transparecer emoções e motivações pessoais, o cientista procura sistemas alternativos para expressar sua subjetividade. É neste universo que se encontram as piadas expostas nos murais dos laboratórios das quais fala Bourdieu e as práticas de autopublicação na internet.

A emergência de práticas de expressão de subjetividades do cientista expõe um cenário no qual a ciência sem espiritualidade não é mais suficiente para a constituição do

\footnotetext{
${ }^{2}$ Os estudos do relativismo epistêmico e de sociologia de Feyerabend (1993) e Kuhn (2005) empreendem uma crítica ao racionalismo ao posicionar a ciência como construção humana movida por sentimentos como o preconceito, a vaidade e a paixão. A prática científica não pode mais se eximir do seu caráter subjetivo, pois é produzida por uma comunidade científica que compartilha um conjunto de crenças e valores.
} 
sujeito-cientista. Foucault segue essa perspectiva ao criticar a negação da espiritualidade operada pela ciência moderna e entender que o conhecimento, tal como está dado, não pode salvar o sujeito e transformá-lo. Ele resulta apenas numa busca infinita por mais conhecimento:

[...] o acesso à verdade, cuja condição doravante é tão-somente o conhecimento nada mais encontrará no conhecimento como recompensa e completude, do que o caminho indefinido do conhecimento. Aquele ponto de iluminação, aquele ponto de completude, aquele momento da transfiguração do sujeito pelo "efeito de retorno" da verdade que ele conhece sobre si mesmo, e que transita, atravessa, transfigura seu ser, nada disto pode mais existir. Não se pode mais pensar que, como coroamento ou recompensa, é no sujeito que o acesso à verdade consumará o trabalho ou o sacrifício, o preço pago para alcançá-la. O conhecimento se abrirá simplesmente para a dimensão indefinida de um progresso cujo fim não se conhece e cujo benefício só será convertido, no curso da história, em acúmulo instituído de conhecimentos ou em benefícios psicológicos ou sociais que, no fim das contas, é tudo o que se consegue da verdade, quando foi tão difícil buscá-la (FOUCAULT, 2004, p.23-24).

A crítica de Foucault tenta, de algum modo, restituir a espiritualidade ao campo científico, pois segundo o teórico, é somente o conhecimento e o acesso à verdade atrelados a um nível espiritual que salvarão o sujeito. A espiritualidade teria o poder de transformar o ethos do sujeito e produzir uma mudança na maneira de existência e de ação deste ser. A restituição de um conhecimento espiritual é também colocada por Japiassú, quando questiona o valor do conhecimento objetivo:

Evidentemente, o conhecimento objetivo pode bastar ao biólogo, ao psicólogo, etc., mas seria capaz de bastar ao homem? Talvez o problema seja mais bem elucidado se concebermos uma passagem do "saber sobre o homem” a um "saber-querer do homem”, este sim, capaz de dirigir sua ação (JAPIASSÚ, 1975, p.14).

O saber-querer do homem de que fala Japiassú seria relacionado a um saber espiritual e se oporia ao saber objetivo do saber sobre o homem, o qual acaba objetivando-o. Segundo entendemos, a cisão entre ciência e espiritualidade não produz somente uma crise no homem comum, como elucidado por Japiassú, mas permite questionamentos do próprio cientista sobre o valor da atividade científica. Além de produzirem mudanças internas no paradigma científico, representadas pelo abandono por parte dos cientistas da imagem neutra e positiva da ciência e adoção de “uma atitude mais crítica e responsável” (JAPIASSÚ, 1975, p.104), 
esses questionamentos levam os cientistas a buscarem outras atividades além da prática científica para se constituírem como sujeitos.

\subsection{Blog: as ferramentas de autopublicação}

A autopublicação na web oferece espaços de construção das subjetividades dos pesquisadores que se apropriam destas ferramentas. Os weblogs, hoje conhecidos como blogs, tornaram-se um meio de os cientistas se comunicarem de maneira informal com um público mais amplo e não-científico e de também construírem uma imagem de si diferente daquele indivíduo isolado em seu laboratório.

O termo weblog surgiu em 1997 e, inicialmente, referia-se a um conjunto de sites que colecionavam e divulgavam links na web (BLOOD, 2000). Foi com o surgimento de ferramentas de publicação, como o blogger, que os blogs popularizaram-se na rede, oferecendo ao seu usuário maior facilidade de publicação e manutenção dos sites, por meio de uma interface amigável (AMARAL; RECUERO; MONTARDO, 2009). O fácil acesso ao modo de publicação do blog permite que essa ferramenta seja utilizada por diversas comunidades, entre elas, a científica.

A emergência de blogs de ciência insere-se no cenário de apropriação de mídias sociais apresentado por Clay Shirky (2011) no livro A cultura da participação. O argumento base defendido pelo autor é que a vontade de participar, de sentir-se importante como indivíduo e como integrante de um grupo socialmente relevante, sempre existiu. A diferença é que as ferramentas de comunicação desenvolvidas no século XX não permitiam colaboração, mas estimulavam isolamento. As mídias sociais do século XXI tornaram-se o meio e representam a oportunidade para extravasar os velhos motivos que nos fazem voltar a ter uma cultura participativa. Os meios - ou seja, as mídias sociais - permitem agora a inclusão do amador no processo de comunicação - neste caso, os cientistas blogueiros.

Os blogs de ciência tornam-se úteis para o meio acadêmico e em algumas áreas de pesquisa já começam a instituírem-se como práticas sociais (KJELLBER, 2009). Com eles, os pesquisadores passam a não depender mais de jornalistas e assessorias de imprensa de suas instituições de pesquisa para disseminarem suas ideias para um público mais amplo. Eles próprios são produtores e editores de seu conteúdo.

Um exemplo do crescimento dos blogs de ciência é a rede brasileira ScienceBlogs Brasil, que congrega atualmente 44 blogs sobre ciência escritos por jornalistas, pesquisadores e amadores. A rede foi criada em 2008 com o nome de Lablogatórios e, segundo Caregnato e 
Sousa (2010), constitui-se no primeiro condomínio de blogs de divulgação científica do Brasil. Em 2009, a rede passou a representar a versão brasileira da rede internacional ScienceBlogs. Em um dos posts do blog Rainha Vermelha Átila Iamarino (2009), um dos administradores da comunidade, comenta essa transição:

O Lablogs entrou no ar em agosto de 2008. De lá para cá crescemos, ganhamos blogs, parceiros e o melhor de tudo, visitantes. Agora, damos um passo maior ainda. Nos associamos (sic) à maior rede de blogs de ciência do mundo. Na verdade, a maior comunidade on-line de ciência. São blogueiros muito competentes, o melhor tipo de vizinhos que podemos ter. Seremos a terceira língua a representar o ScienceBlogs. Além do inglês, até hoje só existia o ScienceBlogs alemão. Mais um motivo para nos orgulharmos do que estamos conquistando.

A associação com a marca ScienceBlogs trouxe prestígio e credibilidade ao condomínio de blogs brasileiro. Atualmente, o site realiza seleções de tempos em tempos para que novos blogs possam integrar a rede, utilizando parâmetros como a qualidade do texto e o tempo de vida do blog candidato.

Uma breve observação dos 20 blogs escritos por pesquisadores do ScienceBlogs Brasil permite-nos descrevê-los como espaços que contém marcas subjetivas do pesquisador que escreve, fazendo surgir o perfil de um cientista que expõe sua visão de mundo na rede. Antes de aparecerem relatos científicos objetivos, os posts mostram impressões pessoais do cientista blogueiro, com comentários, críticas e relatos de experiências do dia a dia do laboratório. Observa-se um viés bem pessoal nos posts, como na figura 1, na qual o cientista blogueiro publicou em seu blog fotos da rotina do seu laboratório. 

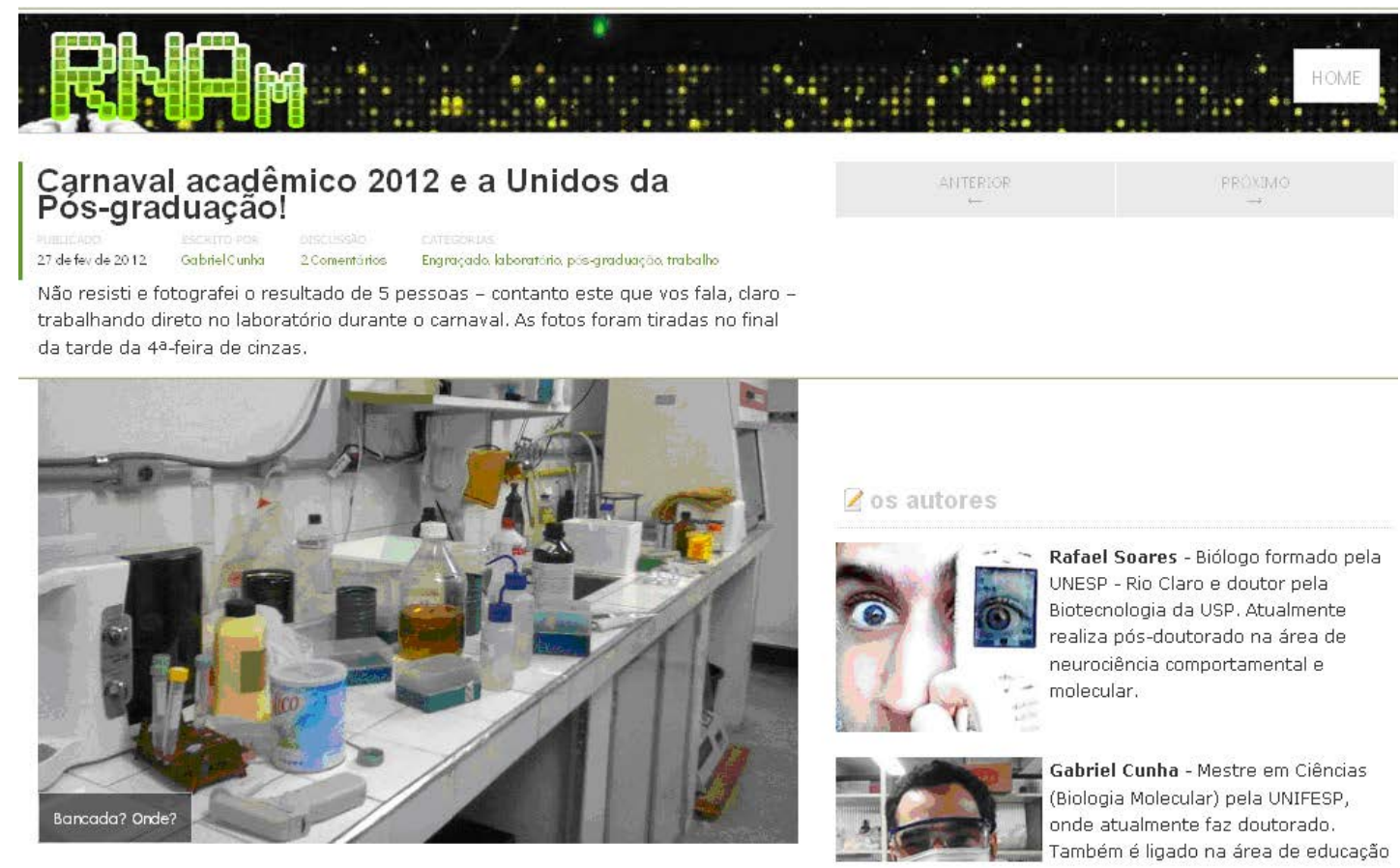

Figura 1 - Post exemplifica viés pessoal dos blogs escritos por pesquisadores

Fonte: http://scienceblogs.com.br/rnam/2012/02/carnaval-academico/

O blog de ciência cumpre o papel de incentivo ao pesquisador para se manter atualizado sobre a sua área de pesquisa, escrever, interagir e criar relacionamentos (KJELLBERG, 2009), atividades essenciais para a práxis científica. O seu viés pessoal o transforma num canal propício para a articulação de redes sociais e conexão entre diversos atores por meio de links e ferramentas de comentários. Por meio dele, o cientista blogueiro cria vínculos e compartilha opiniões nesses espaços de maneira colaborativa.

A utilização de espaços de autopublicação na internet para publicação modifica o próprio perfil deste cientista, o qual passa de um indivíduo isolado em seu laboratório para um indivíduo que convive com seus pares e com o público e que pode vir a construir conteúdos e pesquisas de maneira colaborativa com outros atores. É nesse sentido que podemos pensar a proliferação dos blogs de ciência como a emergência de uma nova cultura de divulgação científica baseada no compartilhamento e na participação.

No contexto da cultura participativa, o blog se coloca como meio do cientista constituir-se como sujeito ao divulgar ciência e fazer a atividade científica circular socialmente. Parece haver uma busca de sentido por parte deste indivíduo, que precisa fazer seu trabalho científico ter relevância além do meio acadêmico, a qual é conseguida por meio da divulgação nos blogs. Produzidos de maneira informal e subjetiva, os textos dos blogs fazem a ciência e o cientista adquirirem um caráter mais humano, próximo do público. Por 
essa razão, esses canais representam indícios de uma abertura da comunidade científica a nãocientistas, pois se direcionam a uma audiência mais ampla utilizando uma linguagem informal para divulgar ciência.

Além da criação de redes, os blogs de ciência servem também como espaços de liberdade aos pesquisadores, à parte da academia, da objetividade do discurso científico e das regras do campo científico. Nestes espaços, os cientistas blogueiros se eximem da responsabilidade de lidar com sistemas de avaliação, relatórios e a lógica do publish or perish da prática científica. As escolhas do que e de como publicar partem do blogueiro, o qual tem total liberdade para postar suas opiniões e impressões. Em alguns casos, os cientistas blogueiros postam críticas ao funcionamento do sistema científico, textos que raramente encontrariam espaço em relatórios e artigos científicos. Na figura 2, por exemplo, o blogueiro critica a falta de discussões sobre a política de acesso aberto na comunidade científica brasileira, tema que já vem sendo debatido em outros países.

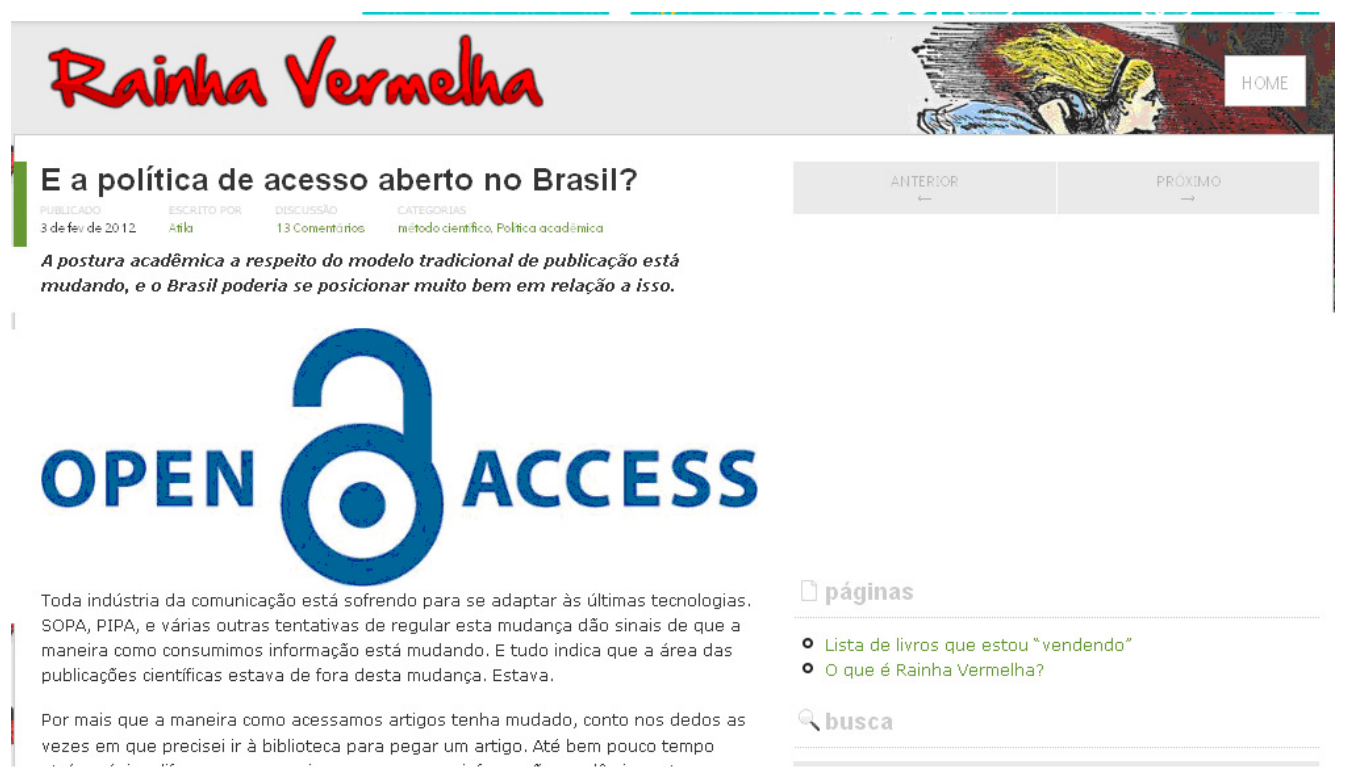

Figura 2 - Blog faz críticas ao funcionamento do sistema científico

Fonte: http://scienceblogs.com.br/rainha/2012/02/acesso-aberto/

A emergência de uma cultura científica colaborativa, representada pelos blogs de ciência, mostra-nos outros modos de constituição do sujeito-cientista longe da individualidade e da objetividade construídas pelo discurso científico na modernidade. Podemos pensar no blog como um espaço de fazer ciência e divulgação científica que engloba motivações 
pessoas do cientista blogueiro e que, por isso, constitui-se como um espaço de cuidado de si do cientista. Discorremos sobre esse tema na próxima seção.

\subsection{0 blog como prática de cuidado de si}

Tratar dos modos de constituição do sujeito cientista por meio de conceitos de Michel Foucault permite entendermos os processos de subjetivação como verdades construídas e, por isso, passíveis de sofrerem modificações. Para produzir-se como sujeito, o indivíduo liga-se a determinadas verdades ao mesmo tempo em que apaga outras tantas possíveis. É nesse sentido que sujeitos se tornam cientistas por meio de técnicas e práticas históricas de subjetivação que apagam suas marcas subjetivas do discurso científico.

Além da construção do ser cientista na modernidade, relacionada à desumanização do cientista, outros modos de subjetivação entram em jogo contemporaneamente, produzindo verdades além da verdade científica e da neutralidade deste indivíduo. Essas construções nos permitem inferir acerca de uma crise no conhecimento pelo conhecimento e de uma tentativa de restituir a espiritualidade a esse saber. É neste contexto que o conceito de cuidado de si de Foucault torna-se importante meio para restituir o lado espiritual das práticas científicas.

Ao designar o cuidado de si da antiguidade como uma atitude geral e forma de atenção voltada a si, Foucault comenta o caráter transformador da prática, a qual se refere a "ações que são exercidas de si para consigo, ações pelas quais nos assumimos, nos modificamos, nos purificamos, nos transformamos e nos transfiguramos” (FOUCAULT, 2004, p.15). Neste sentido, pode-se entender que a reconstituição da espiritualidade do sujeito-cientista requer uma modificação no modo de ser desse sujeito através de práticas discursivas praticadas regularmente, o qual converte seu olhar sobre si mesmo e se subjetiva a discursos que ele reconhece como verdadeiros.

Transformando-se em práticas rotineiras do cientista blogueiro, a publicação em blogs de ciência modifica o modo de subjetivação desse sujeito. Ao utilizar-se dos blogs como forma de expressão, o cientista transforma seu ethos, antes vinculado ao discurso de objetividade do paradigma moderno de ciência, em um ethos relacionado a verdades que permitem que sua subjetividade apareça. Neste sentido, a prática de blogar aparece como conhecimento que transforma a maneira de ser e de se representar do cientista.

De acordo com Foucault (2004), a transformação do ethos na espiritualidade antiga está vinculada a ser o que se diz, ou seja, fazer do discurso verdadeiro a própria forma de ser e de agir do sujeito, vinculando logos (discurso) a ethos. Essa lógica pode ser aplicada aos 
blogs de ciência no momento em que eles somente são bem sucedidos porque o blogueiro acredita na prática da divulgação científica e nas palavras que diz, fundindo o conteúdo de seu blog com a sua própria maneira de ser. Assim, antes de incentivos institucionais, a prática de blogar depende da ação individual do cientista, que precisa acreditar na divulgação científica e molda seu ethos conforme o logos que ele tem como verdadeiro.

Quais as motivações do cientista para moldar seu antigo ethos, construído no isolamento e objetividade, para um cenário de cultura participativa e subjetividade? Em um artigo anterior, utilizamos o raciocínio de Shirky (2011) para compreender que as motivações presentes na cultura participativa não mudaram de contextos anteriores. A comunidade científica e os cientistas sempre se interessaram em divulgar suas pesquisas e instituíram mecanismos de comunicação que ajudassem na disseminação científica. O que muda agora são os meios de expressão utilizados (GOMES; TORACI; FLORES, 2012).

Partindo de Shirky (2011), defendemos que a utilização de blogs de ciência como formas de expressão pelos cientistas contém motivações intrínsecas e extrínsecas As motivações intrínsecas, definidas como "aquelas nas quais a própria atividade é a recompensa” (SHIRKY, 2011, p.68), são as mais valorizadas entre os cientistas, que mantêm entre seus princípios morais o desprendimento para o desenvolvimento da ciência, o bem maior almejado. Além desse alto valor público e socialmente valorizado, outros motivos intrínsecos são visualizados pelos cientistas, como o reconhecimento público da sua pesquisa e do seu esforço intelectual; e o recebimento de contribuições através do debate público para o avanço das pesquisas. Essas motivações intrínsecas se fazem presentes em qualquer processo de comunicação e moldam-se no novo cenário de aproveitamento das novas possibilidades das mídias sociais (GOMES; TORACI; FLORES, 2012).

De outro modo, as motivações extrínsecas também se fazem presentes por meio da visibilidade decorrente da publicação do blog. Por meio dele, os pesquisadores podem ser chamados para ministrar palestras e cursos sob remuneração; eles podem incluem esse trabalho de difusão em seu currículo acadêmico e podem conquistar bolsistas para suas pesquisas. Tantos outros motivos poderão surgir assim como tantos outros usos para um blog poderão ser desenvolvidos por cientistas e amadores de todo o mundo.

Ao discorrer sobre as motivações intrínsecas, Shirky (2011) também apresenta dois desejos relacionados à cultura da participação: desejos de autonomia (decidir o que fazer e como fazer) e competência (ser bom naquilo que fazemos). Podemos associar estas ideias aos cientistas blogueiros, que revelam seu desejo de autonomia dos intermediários da comunicação científica (editores, revisão pelos pares, jornalistas) e a vontade de ter sua 
competência reconhecida por um público mais amplo (ser bom em sua atividade científica, e não necessariamente em manter um blog). Eles podem até ser vistos como amadores em seu trabalho como blogueiros, mas são profissionais em sua atividade científica.

Como meio de estimular desejos de autonomia e competência, os blogs de ciência podem representar uma retomada da espiritualidade negada pelo discurso científico tradicional ao constituírem-se como canais genuínos de expressão das subjetividades do sujeito cientista. Os espaços de autopublicação aparecem como espaços alternativos para produção de modos de ser e discursos distintos do discurso hegemônico da prática científica objetivante.

\section{CONSIDERAÇÕES}

No presente trabalho, pretendeu-se refletir sobre o fenômeno de apropriação de espaços de autopublicação na internet pela comunidade científica, relacionando a prática com o conceito de cuidado de si de Michel Foucault e a construção contemporânea do ethos do cientista. O objetivo era compreender a construção subjetiva dos cientistas nos blogs de ciência e entender as motivações que levam o cientista a utilizar seu tempo na publicação de conteúdos nesses canais.

Compreendemos os blogs de ciência como espaços de cuidado de si do cientista blogueiro, que constrói sua subjetividade afastada do discurso científico formal. Assim como práticas semelhantes anteriores às mídias sociais, essa ocorre como um conhecimento ligado à espiritualidade necessária ao sujeito para transformar-se. Os cientistas buscam na prática de divulgação científica dos blogs justamente esse caráter transformador, acrescentando um sentido e um valor social para a atividade científica que praticam e constituindo-se, assim, como sujeitos.

O enfoque nas tecnologias digitais de autopublicação como práticas de cuidado de si, no entanto, não exclui a existência de outras práticas de mesma ordem na comunidade científica. Assim, os novos meios proporcionam a adaptação de um cenário que já existia anteriormente - como as piadas escritas em laboratórios. A diferença agora é que se disponibiliza uma ferramenta acessível a qualquer cientista e que permite disseminar conteúdos para locais remotos, não mais restritos apenas ao espaço físico do laboratório. 


\section{REFERÊNCIAS}

AMARAL, A; RECUERO, R; MONTARDO, S. Blogs: Mapeando um objeto. In: AMARAL, A; RECUERO, R; MONTARDO, S. (Org.). Blogs.com: estudos sobre blogs e comunicação. São Paulo: Momento Ed., 2009. p.27-53.

BLOOD, R. Weblogs: a history and perspective. 2000. Disponível em: http://www.rebeccablood.net/essays/weblog_history.html. Acesso em 13 de junho de 2012.

BOURDIEU, P. Para uma Sociologia da Ciência. Lisboa: Edições 70, 2008.

CAREGNATO, S.; SOUSA, R. Blogs científicos.br? Um estudo exploratório. Inf.Inf., Londrina, v.15, n.esp, p.56-74, 2010.

FEYERABEND, P. Contra el Método. Barcelona: Planeta De-Agostini S. A. 1993.

FLORES, N. Identidades midiáticas: a construção da identidade de ciência na revista Galileu. 2011. 161f. Dissertação (mestrado em Comunicação)-Programa de Pós-Graduação em Comunicação. Universidade Federal de Santa Maria. 2011.

FOUCAULT, M. A hermenêutica do sujeito. São Paulo: Martins Fontes, 2004.

GOMES, I.; TORACI; V. FLORES, N. Comunicação científica e cultura da participação: análise de blogs de ciência. Anais do XXXV Congresso Brasileiro de Ciências da Comunicação - Fortaleza, CE, Brasil, 3 a 7 de setembro de 2012. Disponível em: http://www.intercom.org.br/sis/2012/resumos/R7-0689-1.pdf.

IAMARINO, A. Mais mudanças. 2009. Disponível em: < http://scienceblogs.com.br/rainha/2009/02/mais-mudancas/ >. Acesso em: 18 jun. 2012.

JAPIASSÚ, H. Nascimento e morte das ciências humanas. Rio de Janeiro: Livraria Francisco Alves, 2 ed., 1982.

. O mito da neutralidade científica. Rio de Janeiro: Imago, 1975.

KJELLBERG, S. I am a blogging researcher: motivations for blogging in scholarly context. First Monday, Bridgman, v.15, n.8, 2 aug. 2010, Disponível em: http://firstmonday.org/htbin/cgiwrap/bin/ojs/index.php/fm/article/view/2962/2580. Acesso em: 13 de junho de 2012.

KUHN, T. La estructura de las revoluciones científicas. Fondo de Cultura Económica de España. 2005.

SANTOS, B.S. Um discurso sobre as ciências. São Paulo: Cortez, 2006.

SHIRKY, C. A cultura da participação: criatividade e generosidade no mundo conectado. Rio de Janeiro: Zahar, 2011. 
Original recebido em: 09/10/2012

Aceito para publicação em: 20/07/2013

Resumo do autor:

Nathalia Flores É graduada em Comunicação Social - Jornalismo pela UFSM, mestre em Comunicação pelo Programa de Pós-Graduação em Comunicação (UFSM). Atualmente é doutoranda em Comunicação no Programa de Pós-Graduação em Comunicação da Universidade Federal de Pernambuco (UFPE). Se dedica principalmente às áreas de jornalismo científico e divulgação científica, identidade da ciência, discurso e editoração gráfica. Participou de um Programa de Acompanhamento das Eleições dos Estados Unidos em 2008, na North Carolina State Univeristy, promovido pela Embaixada dos Estados Unidos no Brasil. 